\title{
Influence of a Pediatric Fruit and Vegetable Prescription Program on Child Dietary Patterns and Food Security
}

\author{
Amy Saxe-Custack ${ }^{1, *(D)}$, Jenny LaChance ${ }^{2} \mathbb{D}$, Jennifer Jess ${ }^{3}$ and Mona Hanna-Attisha ${ }^{4}(\mathbb{D})$ \\ 1 Department of Food Science and Human Nutrition, Division of Public Health, Michigan State \\ University-Hurley Children's Hospital Pediatric Public Health Initiative, 200 E 1st St, Flint, MI 48502, USA \\ 2 Division of Public Health, Michigan State University-Hurley Children's Hospital Pediatric Public Health \\ Initiative, $200 \mathrm{E}$ 1st St, Flint, MI 48502, USA; jlachan1@hurleymc.com \\ 3 Department of Pediatrics and Human Development, Michigan State University College of Human Medicine, \\ 200 E 1st St, Flint, MI 48502, USA; jessjenn@msu.edu \\ 4 Department of Pediatrics and Human Development, Division of Public Health, Michigan State \\ University-Hurley Children's Hospital Pediatric Public Health Initiative, 200 E 1st St, Flint, MI 48502, USA; \\ hannamon@msu.edu \\ * Correspondence: saxeamym@msu.edu; Tel.: +1-810-600-5656
}

Citation: Saxe-Custack, A.;

LaChance, J.; Jess, J.; Hanna-Attisha, M. Influence of a Pediatric Fruit and Vegetable Prescription Program on Child Dietary Patterns and Food Security. Nutrients 2021, 13, 2619. https://doi.org/10.3390/nu13082619

Academic Editor: Jennifer Di Noia

Received: 19 July 2021

Accepted: 27 July 2021

Published: 29 July 2021

Publisher's Note: MDPI stays neutral with regard to jurisdictional claims in published maps and institutional affiliations.

Copyright: (c) 2021 by the authors. Licensee MDPI, Basel, Switzerland. This article is an open access article distributed under the terms and conditions of the Creative Commons Attribution (CC BY) license (https:// creativecommons.org/licenses/by/ $4.0 /)$.

\begin{abstract}
Limited access to fresh foods is a barrier to adequate consumption of fruits and vegetables among youth, particularly in low-income communities. The current study sought to examine preliminary effectiveness of a fruit and vegetable prescription program (FVPP), which provided one USD 15 prescription to pediatric patients during office visits. The central hypothesis was that exposure to this FVPP is associated with improvements in dietary patterns and food security. This non-controlled longitudinal intervention trial included a sample of caregiver-child dyads at one urban pediatric clinic who were exposed to the FVPP for 1 year. Patients received one USD 15 prescription for fresh produce during appointments. A consecutive sample of caregivers whose children were 8-18 years of age were invited to participate in the study. Dyads separately completed surveys that evaluated food security and dietary behaviors prior to receipt of their first prescription and again at 12 months. A total of 122 dyads completed surveys at baseline and 12-month followup. Approximately half of youth were female (52\%), and most were African American (63\%). Mean caregiver-reported household food security improved from baseline to 12 months $(p<0.001)$, as did mean child-reported food security $(p=0.01)$. Additionally, child-reported intake of vegetables $(p=0.001)$, whole grains $(p=0.001)$, fiber $(p=0.008)$, and dairy $(p<0.001)$ improved after 12 months of exposure to the FVPP. This study provides evidence that pediatric FVPPs may positively influence food security and the dietary patterns of children.
\end{abstract}

Keywords: fruit and vegetable prescriptions; food security; children; nutrition

\section{Introduction}

Lifelong dietary patterns are established during childhood and adolescence [1-3]. Influenced by various factors, including caregiver and peer eating behaviors as well as food attitudes, costs, and availability [4-6], consumption patterns during this critical period also play a key role in the development of certain chronic health conditions [3,7-9]. Regrettably, most US children and adolescents fail to consume adequate amounts of high-nutrient foods, particularly fruits and vegetables [10-13], which provide important protections against chronic disease [8,9,14-16]. Persistent environmental challenges to achieving dietary recommendations among youth, particularly in low-income communities, include limited access to and affordability of high-quality, fresh foods [17-21].

Recent efforts to simultaneously address food insecurity and poor dietary behaviors among children and adolescents include the introduction of pediatric fruit and vegetable prescription programs. These programs vary widely in design and approach; however, 
most involve physician-issued prescriptions that may be exchanged for fresh fruits and vegetables at local farmers' markets, mobile markets, or food stores. Although evidence suggests that prescriptions for fruits and vegetables may address barriers to healthy food access among young patients and their families [22-25], reproducible implementation strategies that consistently demonstrate effectiveness are absent.

In August 2015, a large university-affiliated pediatric office, in a low-income, urban area, moved to a downtown farmers' market building. Shortly after this move, the clinic developed and implemented a successful pediatric fruit and vegetable prescription program (FVPP) that provided a pediatrician-issued prescription for fresh produce to patients (birth to 18 years of age) at every office visit [22,26]. This FVPP was expanded to a second pediatric clinic located several miles from the downtown farmers' market in August 2018. The current study sought to examine the preliminary effectiveness of the expanded FVPP, which provided one USD 15 prescription to all pediatric patients at the conclusion of office visits. Prescriptions were redeemable only for fresh produce at either the downtown farmers' market or local mobile market.

\section{Materials and Methods}

\subsection{Study Population}

Flint, Michigan, the birthplace of General Motors, is home to approximately 100,000 residents. Following the American automobile industry's decline, the city fell into an extreme recession [27]. The child poverty rate in Flint is nearly $60 \%$ [28], and the city lacks resources and dietary options. Local stores are likely to offer low-quality foods and few healthy food options [26,29,30], and grocery stores are limited within the city [31].

\subsection{Pediatric Fruit and Vegetable Prescription Program}

Hurley Children's Center, a residency-training clinic with approximately 11,000 visits annually, launched Michigan's first pediatric FVPP in February 2016. The program was intentionally designed to facilitate ease of implementation within busy pediatric offices while sending a ubiquitous message to patients and families regarding the importance of regular consumption of fruits and vegetables. Prescriptions for fresh fruits and vegetables were built into the existing electronic medical record (EMR) system and stored in patient records. This allowed for ease of distribution as well as monthly tracking of prescription distribution rates. Pediatricians ordered prescriptions through the EMR system, printed on prescription paper, and distributed to all patients (birth to 18 years of age) at the conclusion of office visits.

Following the success of the FVPP at Hurley Children's Center [22,26], an identical program was introduced in August 2018 at a private practice pediatric clinic in Flint. This second clinic, Akpinar Children's Clinic, serves approximately 3000 patients. Most patients are residents of Flint and receive public health insurance. Modeled after the original program, fruit and vegetable prescriptions at Akpinar Children's Clinic were ordered via EMR, printed, and given to patients (birth to 18 years of age). All patients, regardless of income or health status, received one USD 15 fruit and vegetable prescription at every clinic visit to be exchanged for fresh produce at either the year-round, downtown farmers' market or a mobile market that also offered free delivery of fresh produce boxes. Prescriptions were treated as vouchers redeemable only for fresh fruits and vegetables and were valid for 90 days from prescription receipt.

\subsection{Study Design}

This was a non-controlled longitudinal intervention trial with a consecutive sample of 122 caregiver-child dyads exposed to the pediatric FVPP for 1 year. Dyads completed inperson assessments at baseline and approximately 6-month and 12-month follow-up with a trained research assistant. Descriptions of the evaluation tools are also available in an earlier article reporting baseline data and a 6-month follow-up on fruit intake [23,32]. The current study was approved by Michigan State University's Institutional Review Board. 


\subsection{Participants and Data Collection}

Beginning in August 2018, pediatric patients at Akpinar Children's Clinic received one USD 15 prescription for fresh produce during each office visit. A consecutive sample of caregivers whose children were between 8 and 18 years of age was invited to participate in this study. Exclusion criteria included the following: caregiver or child not English speaking, legal guardian not present at enrollment, child assent refused, or sibling previously enrolled (study enrollment was limited to 1 caregiver and 1 child per household).

Caregiver-child dyads provided consent and assent before separately answering demographic questions and survey questions that evaluated food security and dietary behaviors. Approximately 12 months after baseline data collection, caregivers returned to the clinic with their children to complete follow-up surveys. All data were collected from August 2018 through March 2020 using a secure digital platform (Michigan State University Qualtrics), accessed through iPads.

\subsection{Evaluation Tools}

\subsubsection{Food Security}

To measure household food insecurity and hunger, caregivers completed the National Center for Health Statistics' US Household Food Security Module: Six Item Short Form [33]. Food security status can be understood using the household's raw score $(0-1=$ high /marginal food security; $2-4=$ low food security; 5-6 = very low food security), calculated by counting affirmative responses ("often", "sometimes", "yes", "almost every month", "some months but not every month").

Children 12 years of age and older $(n=67)$ completed the 9-question Self-Administered Food Security Survey Module for Youth. Because the module's internal validity is adequate for children ages 12 years and older but is not recommended for younger children, the tool was not used with children younger than 12 years of age [34]. The sum of affirmative responses ("a lot" or "sometimes") served as the child's raw score. Food security status can be understood using the raw score $(0-1=$ high $/$ marginal food security; $2-5=$ low food security; 6-9 = very low food security).

\subsubsection{Dietary Behaviors of Children}

The Block Kids Food Screener (BKFS), a 41-item food frequency questionnaire with relatively low administration burden, assessed usual and long-term eating behaviors. Prior research demonstrates it has good relative validity for children and adolescents [35]. The BKFS documented the frequency and quantity of foods and beverages consumed during the previous week and was completed by children with the help of a trained research assistant. Dietary analysis, using the Block Online Analysis System, produced nutrient estimates and number of servings by food group.

\subsubsection{Statistical Analyses}

Demographic data were analyzed using descriptive statistics, specifically means with standard deviations and frequencies with percentages. To compare change at 12 months from baseline, a series of paired t-tests assessed change in mean daily intake of key food groups as well as child-reported food security and household food security. Additionally, independent $t$-tests examined whether mean change in daily intake of vegetables, fruits, fiber, whole grains, and dairy differed by key child demographics (age group, gender, and race/ethnicity). Change in daily intake of vegetables, fruits, fiber, whole grains, and dairy was calculated by subtracting each value at baseline from the daily intake value at 12 months. McNemar analysis was used to determine whether there was a significant increase in the number of children who reported daily consumption of at least $\frac{1}{4}$ cup, $\frac{1}{2}$ cup, and 1 cup of vegetables and fruits at the 12-month follow-up. Finally, multiple logistic regression examined the relationship between key child demographics and those who reported an increase of at least $\frac{1}{4}$ cup of vegetables and fruits at the 12-month follow-up. In relation to logistic regression analyses, for age group, younger age was coded as 1 ; for 
gender, male was coded as 1; and for race/ethnicity, African American was coded as 1. Data were analyzed using IBM SPSS Statistics version 27.

\section{Results}

\subsection{Demographics}

A total of 122 caregiver-child dyads (244 participants) completed surveys at baseline and 12-month follow-up, with the majority (70\%) reporting residency in Flint. As shown in Table 1, approximately half of youth were female (52\%), and most were African American $(63 \%)$. Age of children ranged from 8 to 18 years (mean age $12.42 \pm 2.78$ ). Most caregivers were female (93\%) and African American (59\%). Thirty-seven percent of caregivers reported having a high school degree or less.

Table 1. Child and caregiver demographics.

\begin{tabular}{cccc}
\hline & Demographics & Number & Percentage \\
\hline \multirow{2}{*}{ Dyad residency } & Flint & 86 & 70 \\
& Not Flint & 36 & 30 \\
\hline \multirow{2}{*}{ Child gender } & Male & 58 & 48 \\
& Female & 64 & 52 \\
\hline Child-reported & African American & 77 & 63 \\
race/ethnicity & White & 33 & 27 \\
Child age & Other/Not reported & 12 & 10 \\
\hline (mean age 12.42 \pm 2.78$)$ & 8-12 years & 67 & 55 \\
Caregiver gender & 13-18 years & 55 & 45 \\
\hline \multirow{2}{*}{ Caregiver-reported } & Male & 8 & 7 \\
race/ethnicity & Female & 114 & 93 \\
\hline \multirow{2}{*}{ Caregiver age group } & African American & 72 & 59 \\
(mean age 39.94 \pm 10.28) & White & 35 & 29 \\
& Other/Not reported & 15 & 12 \\
\hline Caregiver education & 25-34 years & 43 & 36 \\
& 35-44 years & 46 & 38 \\
& 45 or more years & 32 & 26 \\
\hline
\end{tabular}

\subsection{Distribution Rate}

From August 2018 through September 2019, a total of 7827 patients (birth to 18 years of age) visited Akpinar Children's Clinic, and 5953 prescriptions for fresh fruits and vegetables were ordered via EMR and distributed to patients. This reflects a $76 \%$ prescription distribution rate during the program's inaugural year.

\subsection{Food Security}

The US Household Food Security Module was completed by 122 caregivers at baseline and 12-month follow-up. Mean household food security score decreased significantly $(p<0.001)$ from baseline $(1.96 \pm 2.20)$ to the 12 -month follow-up $(0.87 \pm 1.25)$, indicating an improvement in food security. There was no difference in change in caregiverreported household food security score by caregiver age group $(p=0.47)$, caregiverreported race/ethnicity $(p=0.85)$, or caregiver education level $(p=0.45)$. A total of 67 children ( $\geq 12$ years of age) completed the Food Security Survey Module for Youth. Mean child-reported food security score also decreased significantly $(p=0.01)$ from baseline $(1.88 \pm 2.06)$ to 12 -month follow-up $(1.04 \pm 1.97)$, indicating an improvement in food security. There was no difference in change in child-reported food security score by child 
age group $(p=0.55)$, gender $(p=0.85)$, or between those who reported race/ethnicity as African American or white $(p=0.12)$.

\subsection{Dietary Behaviors of Children}

The BKFS was completed at baseline and 12-month follow-up by 122 children. As shown in Table 2, children reported improvements in mean daily intake of vegetables $(p=0.001)$, whole grains $(p=0.001)$, fiber $(p=0.008)$, and dairy $(p<0.001)$ after 12 months of exposure to the FVPP. There were no significant differences in change in mean daily intake of vegetables, whole grains, fiber, or dairy by child age group, child gender, or child race/ethnicity (Table 3). Although change in mean daily intake of total fruit in the entire sample of children was not significant, there was a significant difference in mean change of daily fruit intake when comparing consumption of total fruits by race/ethnicity, with African American children reporting a mean decrease of 0.3201 cups of fruit per day and white children reporting a mean increase of 0.209 cups of fruit per day $(p=0.04)$. There was no difference by child age group or gender in reported intake of total fruit (Table 3).

Table 2. Child-reported mean daily intake.

\begin{tabular}{cccc}
\hline Food Group & Timing & Mean \pm SD & $p$ Value \\
\hline \multirow{2}{*}{ Vegetables (cups) } & Baseline & $0.68 \pm 0.62$ & 0.001 \\
& 12 Months & $0.91 \pm 0.43$ & \multirow{2}{*}{0.39} \\
\hline \multirow{2}{*}{ Total fruits (cups) } & Baseline & $1.36 \pm 1.19$ & \multirow{2}{*}{0.008} \\
\hline \multirow{2}{*}{ Fiber (grams) } & 12 Months & $1.26 \pm 0.64$ & \multirow{2}{*}{0.001} \\
\hline \multirow{2}{*}{ Whole grains (ounces) } & Baseline & $10.11 \pm 6.76$ & \multirow{2}{*}{$<0.001$} \\
\hline \multirow{2}{*}{ Dairy (cups) } & 12 Months & $12.10 \pm 4.92$ & \\
\hline
\end{tabular}

Table 3. Comparison of change in key dietary intake by child demographics.

\begin{tabular}{|c|c|c|c|c|c|c|c|c|c|c|c|}
\hline \multirow{2}{*}{\multicolumn{2}{|c|}{ Child Demographics }} & \multicolumn{2}{|c|}{ Vegetables } & \multicolumn{2}{|c|}{ Total Fruit } & \multicolumn{2}{|l|}{ Fiber } & \multicolumn{2}{|c|}{ Whole Grains } & \multicolumn{2}{|l|}{ Dairy } \\
\hline & & Change & $p$ & Change & $p$ & Change & $p$ & Change & $p$ & Change & $p$ \\
\hline Gender & $\begin{array}{l}\text { Male } \\
\text { Female }\end{array}$ & $\begin{array}{l}0.23 \pm 0.73 \\
0.21 \pm 0.70\end{array}$ & 0.88 & $\begin{array}{c}-0.30 \pm 1.26 \\
0.09 \pm 1.20\end{array}$ & 0.08 & $\begin{array}{l}1.98 \pm 8.47 \\
2.01 \pm 7.90\end{array}$ & 0.99 & $\begin{array}{l}0.19 \pm 0.75 \\
0.22 \pm 0.63\end{array}$ & 0.83 & $\begin{array}{l}0.46 \pm 1.44 \\
0.43 \pm 1.11\end{array}$ & 0.91 \\
\hline Race/ethnicity & $\begin{array}{l}\text { African } \\
\text { American } \\
\text { White }\end{array}$ & $\begin{array}{l}0.11 \pm 0.76 \\
0.39 \pm 0.58\end{array}$ & 0.06 & $\begin{array}{c}-0.32 \pm 1.34 \\
0.21 \pm 0.98\end{array}$ & 0.04 & $\begin{array}{l}0.48 \pm 8.46 \\
3.81 \pm 7.30\end{array}$ & 0.05 & $\begin{array}{l}0.14 \pm 0.76 \\
0.31 \pm 0.60\end{array}$ & 0.25 & $\begin{array}{l}0.42 \pm 1.35 \\
0.34 \pm 1.17\end{array}$ & 0.77 \\
\hline Age group & $\begin{array}{l}8-12 \text { years } \\
13-18 \text { years }\end{array}$ & $\begin{array}{c}0.25 \pm 0.72 \\
0.18+0.71\end{array}$ & 0.59 & $\begin{array}{c}0.02 \pm 1.07 \\
-0.24 \pm 1.41\end{array}$ & 0.27 & $\begin{array}{l}2.70 \pm 7.74 \\
1.14 \pm 8.58\end{array}$ & 0.29 & $\begin{array}{l}0.19 \pm 0.70 \\
0.22 \pm 0.69\end{array}$ & 0.84 & $\begin{array}{l}0.44 \pm 1.29 \\
0.45 \pm 1.27\end{array}$ & 0.98 \\
\hline
\end{tabular}

Given the program's focus on improving intake of fruits and vegetables, an examination of the percentage of children who achieved dietary recommendations for mean daily intake of fruits and vegetables was considered. Unfortunately, very few children met current dietary recommendations for fruit and vegetable intake at either timepoint. As a result, we examined the number of children who reported mean daily consumption of at least $\frac{1}{4}$ cup, $\frac{1}{2}$ cup, and 1 cup of vegetables and fruits at baseline and 12-month follow-up (Table 4). There was a significant increase in the number of children who reported daily consumption of at least $\frac{1}{4}$ cup $(p<0.001), \frac{1}{2}$ cup $(p<0.001)$, and 1 cup $(p=0.001)$ of vegetables at the 12-month follow-up. Additionally, there was a significant increase in the number of children who reported daily intake of at least $\frac{1}{2}$ cup $(p=0.02)$ and 1 cup $(p=0.003)$ of total fruits at the 12-month follow-up. 
Table 4. Change in number of children reporting vegetable and fruit intake of at least $\frac{1}{4}, \frac{1}{2}$, and 1 cup.

\begin{tabular}{|c|c|c|c|c|c|c|c|}
\hline \multirow{2}{*}{ Food Group } & \multirow{2}{*}{ Timing } & \multicolumn{2}{|c|}{ At Least $\frac{1}{4}$ Cup } & \multicolumn{2}{|c|}{ At Least $\frac{1}{2}$ Cup } & \multicolumn{2}{|c|}{ At Least 1 Cup } \\
\hline & & $n(\%)$ & $p$ Value & $n(\%)$ & $p$ Value & $n(\%)$ & $p$ Value \\
\hline \multirow{2}{*}{ Vegetables } & Baseline & $97(80 \%)$ & \multirow[t]{2}{*}{$<0.001$} & $62(51 \%)$ & \multirow[t]{2}{*}{$<0.001$} & $26(21 \%)$ & \multirow[t]{2}{*}{0.001} \\
\hline & 12 Months & $116(95 \%)$ & & $103(84 \%)$ & & $50(41 \%)$ & \\
\hline \multirow{2}{*}{ Total Fruits } & Baseline & $107(88 \%)$ & \multirow[t]{2}{*}{0.10} & $93(76 \%)$ & \multirow[t]{2}{*}{0.02} & $63(52 \%)$ & \multirow[t]{2}{*}{0.003} \\
\hline & 12 Months & $115(94 \%)$ & & $107(88 \%)$ & & $83(68 \%)$ & \\
\hline
\end{tabular}

Using a logistic regression, the impact of child race/ethnicity, gender, and age group on the increase of at least a $\frac{1}{4}$ cup in intake of fruits and vegetables was examined. For vegetables, the model was significant $\left(\mathrm{X}^{2}=8.14, p=0.04\right)$, indicating that these demographic variables were predictive of who reported an increase of at least $\frac{1}{4}$ cup intake of vegetables at 12 months. In this model, age group ( $p=0.06,95 \%$ CI $0.97-4.87)$ and gender ( $p=0.51,95 \%$ CI 0.59-2.87) were not significant, while race/ethnicity was significant. Children who reported their race/ethnicity as African American were less likely $(\operatorname{Exp}(B)=0.39,95 \% \mathrm{CI} 0.16-0.93)$ to have increased their daily intake of vegetables by $\frac{1}{4}$ cup at the 12-month visit when compared to children who reported their race/ethnicity as white $(p=0.03)$. For total fruits, the model was also significant $\left(\mathrm{X}^{2}=10.92, p=0.01\right)$. Here, age group ( $p=0.43,95 \%$ CI 0.61-3.23) was not significant, while gender $(\operatorname{Exp}(B)=0.36$, $95 \%$ CI $0.15-0.82, p=0.02)$ and race/ethnicity $(\operatorname{Exp}(B)=0.37,95 \%$ CI $0.15-0.88, p=0.03)$ were significant. Male children and those children who reported their race/ethnicity as African American were less likely to have increased their daily intake of fruit by at least $\frac{1}{4}$ cup at 12 months when compared to female children and those children who reported their race/ethnicity as white, respectively.

\section{Discussion}

Impacting approximately 6.5 million US children, food insecurity is associated with serious consequences that include poor diet quality [36-38], negative health and behavioral outcomes [39-42], and low academic achievement [41,43]. Even intermittent food insecurity, which causes occasional or modest undernutrition among youth, is likely to have longterm neurocognitive and developmental implications [41,44-46]. Pediatricians have a responsibility to screen households with children for food insecurity [47], but resources to address the underlying issues are frequently lacking [48,49]. Previous research has suggested that caregivers whose children were exposed to the pediatric FVPP at Akpinar Children's Clinic perceived the program to be effective in improving household food security, with many describing how they held onto prescriptions to redeem for fruits and vegetables when food resources were depleted [26]. Consistent with this qualitative finding, caregivers and children in the current study reported significant improvements in measured food security following 1 year of exposure to the identical FVPP. Implemented within two distinctly different clinic environments, the FVPP successfully addressed not only food insecurity, but also nutrition security, specifically the provision of healthy foods.

Unique in design, the current FVPP provided prescriptions for fruits and vegetables to all pediatric patients, regardless of health condition or socioeconomic status, to emphasize the important role fruits and vegetables have in health promotion and disease prevention among all children [1-3]. This primary prevention approach is markedly different from previous efforts that have employed produce prescriptions for adults with diet-related chronic health conditions as a disease-management strategy [50-54]. With fruit and vegetable consumption continually falling short of national goals among US children and adolescents [13,55-57], the current program was intentionally designed to send a consistent and straightforward message regarding the importance of fruits and vegetables in a healthy diet. Pediatricians actively promoted that message through the provision of prescriptions that enabled children to purchase fresh, high-quality fruits and vegetables. Previous research has indicated that simply giving fruits and vegetables to children is likely 
to have an important influence on dietary intake through familiarization [21]. Repeated exposure is, in fact, a key mechanism through which youth food acceptance occurs [58,59]. Although participants in the current study failed to meet current dietary recommendations, noteworthy improvements in mean daily consumption of vegetables, whole grain, fiber, and dairy were consistently reported across all age, gender, and ethnic categories. Because greater fruit and vegetable intake during childhood is associated with reductions in chronic diseases in adulthood $[8,9,14-16]$, this particular finding, which is consistent with previous research $[23,25,26]$, highlights the potential long-term implications of pediatric prescriptions for fruits and vegetables.

Although exposure to the FVPP was associated with important dietary improvements among all participants, change in mean daily intake of total fruits differed by race/ethnicity. African American children reported a decrease in total fruit consumption over 12 months, while white children reported an increase in consumption. Further analysis also suggested that, when compared to white children, African American youth were less likely to increase the intake of fruits and vegetables by at least $\frac{1}{4}$ cup. These findings support previous research that has noted similar differences in consumption by race/ethnicity $[11,60]$. The current FVPP may benefit from tailored nutrition education that carefully considers racial/ethnic factors that may influence dietary choices among youth. Additionally, results highlight the continued need to actively address health disparities when implementing similar nutrition interventions.

Recent evidence illustrates parental desire for healthcare systems to not only focus on interventions at the clinic and community levels, but to also advocate for more expansive policies for alleviating barriers to healthy foods [61]. Pediatric prescriptions for fruits and vegetables are increasingly demonstrating effectiveness in combatting food insecurity $[24,26]$ and poor dietary patterns $[23,25,26]$ among children. The current study provides evidence of an effective and reproducible model for widespread prescription distribution within various clinic settings. Although the current initiative was supported by foundation funding through a competitive grants process, opportunities for federal grant support are emerging. Produce prescription programs were added to the US Farm Bill in 2018 through the Gus Schumacher Nutrition Incentive Program. This program allocated USD 25 million toward FVPPs and committed to increasing funding to USD 56 million by 2023 [62].

Limitations of the current study include the lack of a control group. However, pediatricians and community partners questioned whether the inclusion of a control group was ethical when children in Flint are facing hunger and food insecurity. The sample was small and specific to one low-income, urban community. As a result, findings may not be generalizable. However, the current fruit and vegetable prescription program could be modeled in similar communities confronted with enduring obstacles to healthy food access and affordability. Additionally, there may have been selection bias as responses from dyads who chose not to participate may have differed from those who voluntarily enrolled. However, characteristics of the study population closely match those of the source population of predominantly low-income, minority families receiving public health insurance. Finally, the accuracy of the BKFS may be limited by recall bias, but a trained research assistant was consistently available when children completed this instrument to minimize this limitation.

\section{Conclusions}

Pediatricians have a primary role in not only identifying children who are at risk for food insecurity or poor diet and connecting them to community resources, but also in advocating for policies that support access to healthy foods for children of all income levels [47]. The current study provides evidence that fruit and vegetable prescriptions, easily ordered through EMR systems and provided to all pediatric patients, may have a significant influence on food insecurity and dietary patterns of children living in a lowincome, urban community. In addition to monitoring the long-term impact of the FVPP, 
future research will investigate the influence of prescription distribution and redemption patterns on food security and dietary behaviors of children.

Author Contributions: Conceptualization, A.S.-C.; methodology, A.S.-C.; formal analysis, J.L.; writing-original draft preparation, A.S.-C. and J.L.; writing—review and editing, A.S.-C., J.L., J.J. and M.H.-A.; project administration, A.S.-C.; funding acquisition, A.S.-C. All authors have read and agreed to the published version of the manuscript.

Funding: This research was funded by Michigan Health Endowment Fund, grant number 010801-00001

Institutional Review Board Statement: The study was conducted according to the guidelines of the Declaration of Helsinki, and approved by the Institutional Review Board of Michigan State University (protocol code STUDY00000666; date of approval 22 June 2018).

Informed Consent Statement: Informed consent/assent was obtained from all subjects involved in the study.

Data Availability Statement: Requested data may be provided after IRB approval and appropriate data use agreements have been obtained.

Conflicts of Interest: The authors declare no conflict of interest. The funders had no role in the design of the study; in the collection, analyses, or interpretation of data; in the writing of the manuscript, or in the decision to publish the results.

\section{References}

1. Craigie, A.M.; Lake, A.A.; Kelly, S.A.; Adamson, A.J.; Mathers, J.C. Tracking of obesity-related behaviours from childhood to adulthood: A systematic review. Maturitas 2011, 70, 266-284. [CrossRef]

2. Cruz, F.; Ramos, E.; Lopes, C.; Araujo, J. Tracking of food and nutrient intake from adolescence into early adulthood. Nutrition 2018, 55-56, 84-90. [CrossRef] [PubMed]

3. Appannah, G.; Pot, G.K.; Oddy, W.H.; Jebb, S.A.; Ambrosini, G.L. Determinants of a dietary pattern linked with greater metabolic risk and its tracking during adolescence. J. Hum. Nutr. Diet. 2018, 31, 218-227. [CrossRef] [PubMed]

4. Scaglioni, S.; De Cosmi, V.; Ciappolino, V.; Parazzini, F.; Brambilla, P.; Agostoni, C. Factors influencing children's eating behaviours. Nutrients 2018, 10, 706. [CrossRef]

5. McIntosh, A.; Kubena, K.S.; Tolle, G.; Dean, W.; Kim, M.J.; Jan, J.S.; Anding, J. Determinants of children's use of and time spent in fast-food and full-service restaurants. J. Nutr. Educ. Behav. 2011, 43, 142-149. [CrossRef]

6. Palfreyman, Z.; Haycraft, E.; Meyer, C. Parental modelling of eating behaviours: Observational validation of the Parental Modelling of Eating Behaviours scale (PARM). Appetite 2015, 86, 31-37. [CrossRef] [PubMed]

7. Martin, R.M.; Holly, J.M.; Middleton, N.; Davey Smith, G.; Gunnell, D. Childhood diet and insulin-like growth factors in adulthood: 65-year follow-up of the Boyd Orr cohort. Eur. J. Clin. Nutr. 2007, 61, 1281-1292. [CrossRef]

8. Ness, A.R.; Maynard, M.; Frankel, S.; Smith, G.D.; Frobisher, C.; Leary, S.D.; Emmett, P.M.; Gunnell, D. Diet in childhood and adult cardiovascular and all cause mortality: The Boyd Orr cohort. Heart 2005, 91, 894-898. [CrossRef]

9. Saeedi, P.; Shavandi, A.; Skidmore, P.M.L. What do we know about diet and markers of cardiovascular health in children: A review. Int. J. Environ. Res. Public Health 2019, 16, 548. [CrossRef]

10. Drewnowski, A.; Rehm, C.D. Socioeconomic gradient in consumption of whole fruit and $100 \%$ fruit juice among US children and adults. Nutr. J. 2015, 14, 3. [CrossRef]

11. Di Noia, J.; Byrd-Bredbenner, C. Determinants of fruit and vegetable intake in low-income children and adolescents. Nutr. Rev. 2014, 72, 575-590. [CrossRef]

12. Lorson, B.A.; Melgar-Quinonez, H.R.; Taylor, C.A. Correlates of fruit and vegetable intakes in US children. J. Am. Diet. Assoc. 2009, 109, 474-478. [CrossRef] [PubMed]

13. Kim, S.A.; Moore, L.V.; Galuska, D.; Wright, A.P.; Harris, D.; Grummer-Strawn, L.M.; Merlo, C.L.; Nihiser, A.J.; Rhodes, D.G.; Division of Nutrition, Physical Activity, and Obesity, National Center for Chronic Disease Prevention and Health Promotion, CDC. Vital signs: Fruit and vegetable intake among children-United States, 2003-2010. MMWR Morb. Mortal. Wkly. Rep. 2014, $63,671-676$.

14. Hodder, R.K.; Stacey, F.G.; Wyse, R.J.; O’Brien, K.M.; Clinton-McHarg, T.; Tzelepis, F.; Nathan, N.K.; James, E.L.; Bartlem, K.M.; Sutherland, R.; et al. Interventions for increasing fruit and vegetable consumption in children aged five years and under. Cochrane Database Syst. Rev. 2017, 9, CD008552. [CrossRef] [PubMed]

15. Maynard, M.; Gunnell, D.; Emmett, P.; Frankel, S.; Davey Smith, G. Fruit, vegetables, and antioxidants in childhood and risk of adult cancer: The Boyd Orr cohort. J. Epidemiol. Community Health 2003, 57, 218-225. [CrossRef] [PubMed]

16. Laitinen, T.T.; Nuotio, J.; Juonala, M.; Niinikoski, H.; Rovio, S.; Viikari, J.; Rönnemaa, T.; Magnussen, C.G.; Jokinen, E.; Lagström, H.; et al. Success in achieving the targets of the 20-year infancy-onset dietary intervention: Association with insulin sensitivity and serum lipids. Diabetes Care 2018, 41, 2236-2244. [CrossRef] 
17. Morland, K.; Wing, S.; Diez Roux, A. The contextual effect of the local food environment on residents' diets: The atherosclerosis risk in communities study. Am. J. Public Health 2002, 92, 1761-1767. [CrossRef] [PubMed]

18. Baker, E.A.; Schootman, M.; Barnidge, E.; Kelly, C. The role of race and poverty in access to foods that enable individuals to adhere to dietary guidelines. Prev. Chronic Dis. 2006, 3, A76. [PubMed]

19. Walker, R.E.; Keane, C.R.; Burke, J.G. Disparities and access to healthy food in the United States: A review of food deserts literature. Health Place 2010, 16, 876-884. [CrossRef]

20. Zenk, S.N.; Odoms-Young, A.M.; Dallas, C.; Hardy, E.; Watkins, A.; Hoskins-Wroten, J.; Holland, L. "You have to hunt for the fruits, the vegetables": Environmental barriers and adaptive strategies to acquire food in a low-income African American neighborhood. Health Educ. Behav. 2011, 38, 282-292. [CrossRef]

21. Reinaerts, E.; De Nooijer, J.; Candel, M.; De Vries, N. Explaining school children's fruit and vegetable consumption: The contributions of availability, accessibility, exposure, parental consumption and habit in addition to psychosocial factors. Appetite 2007, 48, 248-258. [CrossRef]

22. Saxe-Custack, A.; Sadler, R.; LaChance, J.; Hanna-Attisha, M.; Ceja, T. Participation in a fruit and vegetable prescription program for pediatric patients is positively associated with farmers' market shopping. Int. J. Environ. Res. Public Health 2020, $17,4202$. [CrossRef]

23. Saxe-Custack, A.; LaChance, J.; Hanna-Attisha, M. Child consumption of whole fruit and fruit juice following six months of exposure to a pediatric fruit and vegetable prescription program. Nutrients 2020, 12, 25. [CrossRef] [PubMed]

24. Ridberg, R.A.; Bell, J.F.; Merritt, K.E.; Harris, D.M.; Young, H.M.; Tancredi, D.J. A pediatric fruit and vegetable prescription program increases food security in low-income households. J. Nutr. Educ. Behav. 2019, 51, 224-230.e1. [CrossRef]

25. Ridberg, R.A.; Bell, J.F.; Merritt, K.E.; Harris, D.M.; Young, H.M.; Tancredi, D.J. Effect of a fruit and vegetable prescription program on children's fruit and vegetable consumption. Prev. Chronic Dis. 2019, 16, E73. [CrossRef]

26. Saxe-Custack, A.; Lofton, H.C.; Hanna-Attisha, M.; Victor, C.; Reyes, G.; Ceja, T.; LaChance, J. Caregiver perceptions of a fruit and vegetable prescription programme for low-income paediatric patients. Public Health Nutr. 2018, 21, 2497-2506. [CrossRef] [PubMed]

27. DeWitt, R.D. Pediatric lead exposure and the water crisis in Flint, Michigan. JAAPA 2017, 30, 43-46. [CrossRef]

28. U.S. Census Bureau. 2014-2018 American Community Survey 5-year estimates, Table DP03: Selected Economic Characteristics. Available online: https:/ / data.census.gov/cedsci/table?q=DP03\&g=1600000US2629000\&tid=ACSDP5Y2018.DP03\& hidePreview=true (accessed on 15 May 2021).

29. Shaver, E.R.; Sadler, R.C.; Hill, A.B.; Bell, K.; Ray, M.; Choy-Shin, J.; Lerner, J.; Soldner, T.; Jones, A.D. The Flint Food Store Survey: Combining spatial analysis with a modified Nutrition Environment Measures Survey in Stores (NEMS-S) to measure the community and consumer nutrition environments. Public Health Nutr. 2018, 21, 1474-1485. [CrossRef] [PubMed]

30. Mayfield, K.E.; Carolan, M.; Weatherspoon, L.; Chung, K.R.; Hoerr, S.M. African American women's perceptions on access to food and water in Flint, Michigan. J. Nutr. Educ. Behav. 2017, 49, 519-524.e1. [CrossRef]

31. Sadler, R.C. Integrating expert knowledge in a GIS to optimize siting decisions for small-scale healthy food retail interventions. Int. J. Health Geogr. 2016, 15, 19. [CrossRef]

32. Saxe-Custack, A.; LaChance, J.; Hanna-Attisha, M.; Ceja, T. Fruit and vegetable prescriptions for pediatric patients living in Flint, Michigan: A cross-sectional study of food security and dietary patterns at baseline. Nutrients 2019, 11, 1423. [CrossRef]

33. Blumberg, S.J.; Bialostosky, K.; Hamilton, W.L.; Briefel, R.R. The effectiveness of a short form of the Household Food Security Scale. Am. J. Public Health 1999, 89, 1231-1234. [CrossRef] [PubMed]

34. Connell, C.L.; Nord, M.; Lofton, K.L.; Yadrick, K. Food security of older children can be assessed using a standardized survey instrument. J. Nutr. 2004, 134, 2566-2572. [CrossRef]

35. Hunsberger, M.; O'Malley, J.; Block, T.; Norris, J.C. Relative validation of Block Kids Food Screener for dietary assessment in children and adolescents. Matern. Child. Nutr. 2015, 11, 260-270. [CrossRef] [PubMed]

36. Landry, M.J.; van den Berg, A.E.; Asigbee, F.M.; Vandyousefi, S.; Ghaddar, R.; Davis, J.N. Child-report of food insecurity is associated with diet quality in children. Nutrients 2019, 11, 1574. [CrossRef] [PubMed]

37. Rodriguez, L.A.; Mundo-Rosas, V.; Mendez-Gomez-Humaran, I.; Perez-Escamilla, R.; Shamah-Levy, T. Dietary quality and household food insecurity among Mexican children and adolescents. Matern. Child. Nutr. 2017, 13, e12372. [CrossRef] [PubMed]

38. Eicher-Miller, H.A.; Zhao, Y. Evidence for the age-specific relationship of food insecurity and key dietary outcomes among US children and adolescents. Nutr. Res. Rev. 2018, 31, 98-113. [CrossRef]

39. Casey, P.H.; Simpson, P.M.; Gossett, J.M.; Bogle, M.L.; Champagne, C.M.; Connell, C.; Harsha, D.; McCabe-Sellers, B.; Robbins, J.M.; Stuff, J.E.; et al. The association of child and household food insecurity with childhood overweight status. Pediatrics 2006, 118, e1406-e1413. [CrossRef] [PubMed]

40. Metallinos-Katsaras, E.; Must, A.; Gorman, K. A longitudinal study of food insecurity on obesity in preschool children. J. Acad. Nutr. Diet. 2012, 112, 1949-1958. [CrossRef]

41. Shankar, P.; Chung, R.; Frank, D.A. Association of food insecurity with children's behavioral, emotional, and academic outcomes: A systematic review. J. Dev. Behav. Pediatr. 2017, 38, 135-150. [CrossRef]

42. Howard, L.L. Transitions between food insecurity and food security predict children's social skill development during elementary school. Br. J. Nutr. 2011, 105, 1852-1860. [CrossRef] 
43. Fought, E.L.; Williams, P.L.; Willows, N.D.; Asbridge, M.; Veugelers, P.J. The association between food insecurity and academic achievement in Canadian school-aged children. Public Health Nutr. 2017, 20, 2778-2785. [CrossRef] [PubMed]

44. Cook, J.T.; Black, M.; Chilton, M.; Cutts, D.; Ettinger de Cuba, S.; Heeren, T.C.; Rose-Jacobs, R.; Sandel, M.; Casey, P.H.; Coleman, S.; et al. Are food insecurity's health impacts underestimated in the U.S. population? Marginal food security also predicts adverse health outcomes in young U.S. children and mothers. Adv. Nutr. 2013, 4, 51-61. [CrossRef]

45. Grineski, S.E.; Morales, D.X.; Collins, T.W.; Rubio, R. Transitional dynamics of household food insecurity impact children's developmental outcomes. J. Dev. Behav. Pediatr. 2018, 39, 715-725. [CrossRef] [PubMed]

46. Ryu, J.H.; Bartfeld, J.S. Household food insecurity during childhood and subsequent health status: The Early Childhood Longitudinal Study-Kindergarten Cohort. Am. J. Public Health 2012, 102, e50-e55. [CrossRef] [PubMed]

47. Council on Community Pediatrics; Committee on Nutrition. Promoting food security for all children. Pediatrics 2015, 136, e1431-e1438. [CrossRef]

48. Barnidge, E.; LaBarge, G.; Krupsky, K.; Arthur, J. Screening for food insecurity in pediatric clinical settings: Opportunities and barriers. J. Community Health 2017, 42, 51-57. [CrossRef] [PubMed]

49. Makelarski, J.A.; Abramsohn, E.; Benjamin, J.H.; Du, S.; Lindau, S.T. Diagnostic accuracy of two food insecurity screeners recommended for use in health care settings. Am. J. Public Health 2017, 107, 1812-1817. [CrossRef]

50. Bryce, R.; Guajardo, C.; Ilarraza, D.; Milgrom, N.; Pike, D.; Savoie, K.; Valbuena, F.; Miller-Matero, L.R. Participation in a farmers' market fruit and vegetable prescription program at a federally qualified health center improves hemoglobin A1C in low income uncontrolled diabetics. Prev. Med. Rep. 2017, 7, 176-179. [CrossRef] [PubMed]

51. Trapl, E.S.; Smith, S.; Joshi, K.; Osborne, A.; Benko, M.; Matos, A.T.; Bolen, S. Dietary impact of produce prescriptions for patients with hypertension. Prev. Chronic Dis. 2018, 15, E138. [CrossRef]

52. Cavanagh, M.; Jurkowski, J.; Bozlak, C.; Hastings, J.; Klein, A. Veggie Rx: An outcome evaluation of a healthy food incentive programme. Public Health Nutr. 2017, 20, 2636-2641. [CrossRef]

53. Friedman, D.B.; Freedman, D.A.; Choi, S.K.; Anadu, E.C.; Brandt, H.M.; Carvalho, N.; Hurley, T.G.; Young, V.M.; Hébert, J.R. Provider communication and role modeling related to patients' perceptions and use of a federally qualified health center-based farmers' market. Health Promot. Pract. 2014, 15, 288-297. [CrossRef] [PubMed]

54. Muhammad, H.; Reeves, S.; Ishaq, S.; Mayberry, J.; Jeanes, Y.M. Adherence to a gluten free diet is associated with receiving gluten free foods on prescription and understanding food labelling. Nutrients 2017, 9, 705. [CrossRef] [PubMed]

55. Shook, R.P.; Halpin, K.; Carlson, J.A.; Davis, A.; Dean, K.; Papa, A.; Sherman, A.K.; Noel-MacDonnell, J.R.; Summar, S.; Krueger, G.; et al. Adherence with multiple national healthy lifestyle recommendations in a large pediatric center electronic health record and reduced risk of obesity. Mayo Clin. Proc. 2018, 93, 1247-1255. [CrossRef]

56. Banfield, E.C.; Liu, Y.; Davis, J.S.; Chang, S.; Frazier-Wood, A.C. Poor adherence to US dietary guidelines for children and adolescents in the National Health and Nutrition Examination Survey population. J. Acad. Nutr. Diet. 2016, 116, 21-27. [CrossRef]

57. Slining, M.M.; Mathias, K.C.; Popkin, B.M. Trends in food and beverage sources among US children and adolescents: 1989-2010. J. Acad. Nutr. Diet. 2013, 113, 1683-1694. [CrossRef] [PubMed]

58. Johnson, S.L. Developmental and environmental influences on young children's vegetable preferences and consumption. Adv. Nutr. 2016, 7, 220S-231S. [CrossRef]

59. Wadhera, D.; Capaldi Phillips, E.D.; Wilkie, L.M. Teaching children to like and eat vegetables. Appetite 2015, 93, 75-84. [CrossRef]

60. Trude, A.C.; Kharmats, A.Y.; Hurley, K.M.; Anderson Steeves, E.; Talegawkar, S.A.; Gittelsohn, J. Household, psychosocial, and individual-level factors associated with fruit, vegetable, and fiber intake among low-income urban African American youth. BMC Public Health 2016, 16, 872. [CrossRef] [PubMed]

61. DeWit, E.L.; Meissen-Sebelius, E.M.; Shook, R.P.; Pina, K.A.; De Miranda, E.D.; Summar, M.J.; Hurley, E.A. Beyond clinical food prescriptions and mobile markets: Parent views on the role of a healthcare institution in increasing healthy eating in food insecure families. Nutr. J. 2020, 19, 94. [CrossRef]

62. White, N.D. Produce prescriptions, food pharmacies, and the potential effect on food choice. Am. J. Lifestyle Med. 2020, 14, 366-368. [CrossRef] [PubMed] 